\title{
DA NECESSIDADE DA EVOLUÇÃO DO DIREITO E DA JUSTIÇA: OS MEIOS NÃO ADVERSARIAIS DE RESOLUÇÃO DE CONFLITOS NO BRASIL E NO DIREITO ALIENÍGENA
}

\author{
Jane Elisabeth Cesca $^{1}$ \\ Thomaz Cesca Nunes ${ }^{2}$
}

\begin{abstract}
RESUMO: O artigo trata das possibilidades de soluções consensuais dos conflitos familiares, de consumidores, vizinhos, penais, e outros, de forma pacífica e diversa daquela com a qual a população está acostumada a lidar. Indica métodos não adversariais de resolução, tanto judiciais como extrajudiciais, como forma de se obter respostas céleres, uma justiça menos onerosa, e com capacidade de fornecer suporte para o desenvolvimento de um ser humano autônomo e mais feliz. Tais soluções vêm ao encontro dos anseios dos cidadãos e possibilitam, com isso, uma menor ingerência do Estado na vida privada. Apresenta variados métodos de resolução não adversariais de litígios utilizados em Portugal, Estados Unidos, Espanha, Argentina e Brasil.
\end{abstract}

PALAVRAS-CHAVE: mediação, conciliação, negociação, arbitragem, múltiplas portas, julgados de paz, famílias, vizinhos, menores, idosos, situação de risco, psicologia, emoções, direito comparado.

\section{From the necessity of evolution of Law and Justice: the non-adversarial methods of resolution of litigations in Brazilian and Foreign Law}

\begin{abstract}
The article deals with the possibilities of solutions of the familiar conflicts, of consumers, criminal, and others, of pacific and diverse form of that one with which if it is accustomed. It indicates methods without quarrels of resolution, judicial as in such a way extrajudicial, to get a reply, through a justice less onerous and capable to supply support the development of an independent and happy human being. Such solutions come to the meeting of the yearnings of the population and make possible, with this, a lesser mediation of the State in the private life. It presents not adversarial methods of resolution of litigations of Portugal, United States, Spain, Argentina and Brazil.
\end{abstract}

KEY-WORDS: mediation, conciliation, negotiation, arbitration, forum of multiple doors, judged of peace families, neighbors, minors, aged, situation of risk, comparative jurisprudence.

\footnotetext{
${ }^{1}$ Mestre pela Universidade Federal de Santa Maria. Docente do Curso de Direito da Faculdade Estácio de Sá de Santa Catarina e do Curso de Direito da CESAG, de São José/SC. Supervisora do Centro Interdisciplinar de Mediação da Universidade do Sul de Santa Catarina (Unisul). Mediadora Familiar. Advogada.

${ }^{2}$ Acadêmico do $7^{\circ}$ semestre da Pontifícia Universidade Católica do Rio Grande do Sul. Estagiário do Foro de Porto Alegre/RS.
} 


\section{Introdução}

Os conflitos e as desavenças são aspectos inevitáveis e decorrentes da vida. Tem funções individuais e sociais valiosas: proporcionam o estímulo que concorre para as mudanças sociais e o desenvolvimento psicológico individual. Os chineses ensinam que a palavra conflito é composta por dois sinais superpostos: um quer dizer perigo, e o outro, a oportunidade. O perigo é ficar num impasse que retira as energias individuais; a oportunidade refere-se a considerar as opções existentes e abrir-se a novos caminhos, que permitam outras relações entre os indivíduos, e criar meios de solucionar os problemas do dia-a-dia. A visão atual da sociedade moderna é que o conflito faz parte da vida humana, e não deve ser nem evitado nem suprimido, mas gerenciado com eficácia.

A possibilidade de ver solucionado o conflito de forma pacífica e diversa daquela com a qual se está acostumado, vem ao encontro de anseios da sociedade que deseja uma justiça célere e capaz de fornecer suporte para o desenvolvimento de um ser humano autônomo e mais feliz, diminuindo com isso a ingerência do Estado na vida privada. Hoje o maior problema da Justiça é a morosidade. De que adianta os direitos republicanos estarem estampados aos olhos de todos, se não existem mecanismos céleres para lhes dar validade e vitalidade? Cada vez mais entende-se que delegar uma parcela da competência do Estado, pode ser a solução para vários tipos de desavenças.

Na dialética da liberdade, o homem precisa sintetizar o necessário e o possível, e tanto o necessário quanto o possível variam através da história. Mas para a sintetização, sendo responsabilidade do próprio indivíduo existente, não há parâmetros fornecidos definitivamente. E a ética da liberdade tem o mérito de exigir constantemente o respeito a cada ser humano. (ABBAGNANO, 1970, p. 57).

O Direito como princípio, é o começo para uma base, é honestidade, é não lesar. Dar a cada um o que é seu deve ser norma de comportamento natural, comum. O objetivo do Direito é o estudo das normas jurídicas escritas, é oferecer os elementos essenciais ao seu conhecimento, em termos de linguagem e de métodos, com uma visão preliminar das partes que o compõe e de sua complementaridade, bem como sua situação da história da cultura. A doutrina da cultura ou dos valores é uma formulação moderna dos problemas da filosofia e das ciências. No plano jurídico sustenta que o direito, como a ciência, a arte e os demais fenômenos sociais, pertencem ao reino da cultura, ao mundo construído pelo homem, através do tempo. 
Se o "conhece a ti mesmo" foi à preocupação central da filosofia de Sócrates, se o conhecimento do mundo físico é a nota dominante da ciência moderna; o propósito básico dos culturalistas poderia ser assim sintetizado: "Homem, conhece a obra de teu espírito" (REALE, 1994, p. 203).

$\mathrm{Na}$ necessidade de se ver o direito como um fenômeno inserido em situações essenciais, dotado de um sentido próprio, a ciência jurídica surge como uma ciência cultural para as pessoas, e não como conhecimento que constitui uma unidade imanente, de base concreta e real, que repousa sobre valorações. É por isso que:

(...) as mais recentes conquistas no campo da epistemologia jurídica situam-se no culturalismo jurídico, que concebe o direito como um objeto criado pelo homem, dotado de um sentido de conteúdo valorativo, sendo, portanto, pertencente ao campo da cultura. (NADER, 2000, p. 26).

Sabe-se que há muitos caminhos ligados à filosofia, à moral, a ética de cada um, que explanam dimensões e caminhos acerca do Direito como regulador das normas. Origem, ramos de formação, funções e classificações. O Direito é núcleo da evolução do próprio homem e por todos os séculos, acompanha e ampara os conflitos para que o bem comum seja um objetivo alcançado por todos. É assim relacionado que o desenvolver deste estudo pretende abranger como o Direito pode solucionar os conflitos, pregando o mecanismo da solução não adversarial dos mesmos.

\section{A justiça moderna}

O Estado de Direito foi o mais útil elemento à compreensão do fenômeno jurídico positivo e ao desenvolvimento da ciência jurídica, por intermédio de uma visão que cede o mais alto significado a dogmática jurídica, já a partir do patamar constitucional. Isto por que no Brasil, o Direito sempre foi um conceito vago, que significou (a) em várias oportunidades privilégios para alguns. Em seus 500 anos, foi o autoritarismo e não o Direito que permeou as relações na sociedade, e entre ela e o Estado. Marcas de uma colonização exploratória que se perpetuam pelos séculos da história nacional.

Agora, vive-se na sociedade de risco (GIDDENS, 1997, p.16), um tempo de transformações, das desincorporações e reincorporações. A Justiça não pode mais conviver com estruturas e fórmulas jurássicas. O poder que se propõe à preservação da ordem legal é 
extremamente conservador, engessado. O direito é consagrado pela decisão, mas essa não se materializa. Numa linguagem bem popular, é o "ganha mais não leva". "Ninguém nos dias de hoje poderá fazer um diagnóstico diferente de nossa atividade judicante" (MARTINS, 2003, p. 66).

A lei da arbitragem, a mediação, os juizados especiais são meios de resolução válidos para melhor enfrentarem-se as desavenças surgidas da convivência social. Mas, estas medidas reduziram pouco a carga dos choques, que se agigantaram numa sociedade em transformação, na qual o Brasil se encontra. Ainda são métodos pouco reconhecidos e aceitos pela população leiga, provável grande beneficiada destes meios.

Para nós os problemas da justiça devem ser situados em duas fronteiras: no que se refere à modificação das leis processuais e no que se refere à estrutura interna dos serviços. A reforma do Judiciário, apesar da seriedade com que vem sendo tratada, preocupou-se mais com a parte institucional do sistema do que propriamente com a melhor viabilização dos serviços. $\mathrm{O}$ problema do processo no Brasil só se resolverá de forma satisfatória quando alguém legislar corajosamente no sentido de minimizar os recursos, especialmente os que se referem às instâncias excepcionais de Brasília.

O S.T.F. deve restringir-se ao exame das questões constitucionais, cuja relevância declara e não interferir nas questões de caráter estadual. Ao cidadão, na forma constitucional, há de ser deferida a mais ampla defesa nos limites que a lei estabelece sem perder de vista à macro visão do sistema judiciário. O processo de execução, que já foi tratado pela Comissão, pode também ser simplificado ainda mais, para assim, criarem-se outros encargos para o executado brandir os recursos. (MARTINS, 2003, p. 94 e 95).

Nenhuma organização tão extensa como a brasileira pode abstrair de um aconselhamento técnico capaz de melhor viabilizar o fluxo dos processos. De outra forma ninguém pode lidar com os grandes números sem a ajuda das tecnologias hoje disponíveis. Quando se diz que a Justiça está informatizada há, na verdade, certo exagero. O que se pode dizer é que na Justiça moderna todos dispõe de computador como ferramenta indispensável de consulta e funcionalidade para os recursos. Porém, quanto os atos judiciais, estes ainda são feitos de forma "campeira" quando se poderia, sem prejuízo de qualquer espécie, realizá-los pela via eletrônica. 
Há situações onde se diz que o Estado é o maior interessado em que a Justiça continue lerda e ineficiente, incapaz de fazer valer as suas decisões, pois estas onerariam sobremaneira os cofres públicos, uma vez que ele mesmo é o maior partícipe processual.

É fundamental para o funcionamento correto do exercício dos direitos que se faça uma revisão dessas estruturas de serviço, dos costumes e dos caminhos obsoletos de prestar a jurisdição. Para que um Estado possa garantir os direitos de seus cidadãos, necessário dispor de uma boa organização, tecnologia, agilidade e competência, para não citar outras características, não menos importantes, dos Três Poderes em que se divide.

É certo que o Judiciário não é perfeito e que precisa ser remodelado. A expectativa do corpo social é grande, e embora a edição da Emenda Constitucional $\mathrm{n}^{\circ}$. 45, que tratou, por exemplo, "da duração razoável do processo", nada parece ter mudado. Será por excesso de trabalho, má organização judicial, a complexidade processual, recursos em demasia? Interessante aguardar "um tempo razoável", e depois comparar como era, e como está depois da citada Emenda.

Se a análise for realizada sobre cada magistrado, não muda nada. O juiz do feito não tem a possibilidade, de melhorar esta situação geral para diminuir estes descompassos. Também faltam instrumentos ao Judiciário para lidar com a esfera afetiva e psíquica dos afetos e desejos, e com a esfera psico-social (papéis e funções) dos vínculos desfeitos.

O magistrado não possui tempo nem condições de avançar nestas searas. Então, necessário que se estabeleçam novas formas ou se utilizem de forma plural os procedimentos consensuais existentes na atualidade, sem a intervenção direta da atuação do Judiciário, para beneficiar a população na busca pela resposta dos seus direitos. Afinal, o Judiciário não possui o monopólio da Justiça, e sim da jurisdição.

\section{Os meios extrajudiciais de resolução de conflitos e a legislação nacional}

O juiz continua é visto como um mito para boa parte da população, o processo e sua tramitação são coisas distantes, difíceis de ser entendidos, ambos responsáveis por "dizer e demarcar o direito" dos cidadãos, que muitas vezes não absorvem o resultado de uma audiência em vista do linguajar jurídico.

Dizer mesmo, impor a lei, perante as provas apresentadas e a manifestação dos advogados. Esta é a forma estatal de colocar fim a um litígio, mas entende-se que existem possibilidades de solução através de outros instrumentos, equivalentes a jurisdição estatal. 
Afinal, será que alguém cumpre ou tem disposição para cumprir eficientemente alguma solução que lhe seja imposta? O ser humano pode ser feliz, não podendo se manifestar, sem poder dizer o que sente, não tendo a oportunidade de ser ouvido atentamente, no desenrolar do processo? É claro que existem outros instrumentos equivalentes, mas desconhecidos do público em geral, uma vez que a cultura nacional para resolução de conflitos é a processual, do enfrentamento, onde sempre haverá um vencedor e um vencido, e onde quem realmente se manifesta são os procuradores dos partícipes e o magistrado.

$\mathrm{Na}$ atualidade, a maioria dos conflitos em matéria de consumo caracteriza-se por uma desproporção entre os interesses econômicos em jogo e o custo da respectiva resolução judicial. Com o objetivo de resolver os problemas específicos dos litígios de consumo, vários países têm preferido soluções extrajudiciais cuja flexibilidade vem ao encontro das necessidades dos consumidores e dos fornecedores, profissionais, etc. Por quê? Porque estes métodos concedem as seguintes vantagens: baixo custo, a rapidez, informalidade, escuta ativa, possibilidade de poder participar da decisão (salvo na arbitragem), e possuem credibilidade. Não há, também, o desgaste emocional de anos e anos a espera de uma solução.

O novo Código Civil - Lei $n^{\circ}$. 10.406, de 10 de janeiro de 2002, trata da matéria nos artigos 851 a 853, estabelecendo que "é admitido compromisso, judicial ou extrajudicial, para resolver litígios entre pessoas que podem contratar". (art. 851). Por sua vez, o Código de Processo Civil, reza em seu artigo 86: "As causas cíveis serão processadas e decididas, ou simplesmente decididas pelos órgãos jurisdicionais, nos limites de sua competência, ressalvada às partes a faculdade de instruírem juízo arbitral". No projeto de lei existente sobre mediação, projeto $n^{\circ} .4827 / 1988$, em seu artigo $4^{\circ}$, observa-se que:

Art. $4^{o}$ Em qualquer tempo e grau de jurisdição, pode o juiz buscar convencer as partes da conveniência de se submeterem a mediação extrajudicial, ou, com a concordância delas, designar mediador, suspendendo o processo pelo prazo de até três meses, prorrogável por igual período.

É o legislador brasileiro abrindo o caminho para a pluralidade de meios de solução das divergências existentes entre as partes. Bons ventos, que já vem sendo explorados em alguns Tribunais (como o de Santa Catarina, na comarca de Tubarão), mesmo sem a edição da lei específica, antes mencionada, que recentemente (julho de 2006) teve sua "poeira afastada" através do substitutivo apresentado pelo senador Pedro Simon (PMDB-RS), ao projeto de lei (PLC 94/2002) da deputada Zulaiê Cobra (PSDB-SP), institucionalizando e disciplinando a 
mediação como método de prevenção e solução consensual de conflitos na esfera civil. Agora, o projeto volta à Câmara dos Deputados, para nova análise. Enfim, uma movimentação, embora apenas para a área cível, se assim aprovado for.

Os recursos extrajudiciais mais explorados em vários países do mundo são a mediação, a conciliação, a negociação e a arbitragem. A eles, a devida importância é consignada a seguir.

\subsection{A Mediação}

A Mediação é uma forma de tentativa de resolução de conflitos através de um terceiro, estranho ao conflito, que atuará como um de "facilitador", buscando estabelecer um ponto de equilíbrio na controvérsia sem interferir na decisão final dos opostos, que o escolheram”. Sua função é a de aproximar as partes, captando os interesses que ambas têm em comum, com a finalidade de objetivar uma solução que seja a mais justa possível para as mesmas. (MEDIAR, 2005). Este profissional precisa ser uma pessoa com competência técnica, ou seja, é necessário que tenha capacitação, que envolve o conhecimento básico de psicologia, sociologia, técnicas de escuta e comunicação, formas de manejo dos conflitos, dentre outros. Uma das grandes vantagens da Mediação é que ela pode evitar um longo e desgastante processo judicial, pois a mesma se dá antes que as partes se definam por uma briga nos tribunais, resolvendo suas diferenças de forma extrajudicial, levando ao Judiciário só aquelas questões que não podem ser resolvidas de outra forma. De acordo com RISKIN (2002, p.70-710), a mediação é uma negociação facilitada, sendo que a maioria dos doutrinadores observa duas abordagens principais:

(...) categorias adversarial e não adversarial (focalizada esta na solução de problemas). A abordagem adversarial geralmente supõe que a negociação será focalizada num recurso limitado - como o dinheiro - e que as partes decidirão se o dividem e como o fazem. Por essa visão, as metas das partes entram em conflito - o que uma ganha, a outra tem que perder.

Podem ser indicadas como situações exemplos para serem mediadas as desavenças de vizinhança, separação, divórcio, guarda de filhos, desamparo de idosos e conflitos trabalhistas, dentre outros. A mediação insere-se numa orientação de sociedade que encoraja a autopromoção, a comunicação e a responsabilidade: 
Ela visa à mudança cultural no que diz respeito ao poder dos indivíduos de tomar eles mesmos suas próprias decisões. Ela evita a escalada dos desentendimentos, da amargura, da depressão, da violência, não deixando as partes chegar ao conflito extremo, até então permitido em nosso sistema adversarial. É de ser mencionada a possível "colaboração de profissionais de saúde mental, quando o mediador estiver tratando de litígio crônico, onde um dos pais exprime desconfiança, ódio, medo e culpa projetada no outro e até nos filhos”. (GRUNSPUN, 2000, p.94)

A realidade pode ser bem negativa, com base em violência, negligência, drogas, alcoolismo, em famílias de intenso conflito, e isso pode levar a inquéritos policiais. Ou os problemas pessoais dos pais podem ter origem na infância dos mesmos, por carências e perdas. Segundo GRUNSPUN (2000, p. 94), existem pais que:

(...) não conseguem amadurecer e, por insegurança, alimentam conflitos conjugais exageram nas reivindicações no tribunal. No entanto, os problemas com os filhos precisam de uma decisão que pode ser mais adequada através de mediação do que de uma sentença de um juiz. O mediador é capaz de atenuar idéias de vingança e manter uma continuidade de alianças e maiores responsabilidades para o futuro dos filhos.

As funções dos profissionais de saúde mental situam-se em quatro grupos gerais: "testemunha especialista; diagnóstico, terapia, aconselhamento e orientação; tomar decisão e educação". (GRUNSPUN, 2000, p. 95) Nos tribunais estes profissionais, sejam médicos, psiquiatra, psicólogo, assistente social, fonoaudiólogo e outros, são convocados pelas partes ou pelo magistrado e seu testemunho pode ser importante para tomada da decisão judicial. Já na mediação, eles não prestam testemunho, mas podem ser convocados pelo mediador para auxiliar em acordos, principalmente se um dos filhos já estiver sendo assistido, sem a aquiescência de um dos partícipes.

A ideologia ganhador-perdedor vigente no sistema tradicional judicial é substituída por uma nova abordagem baseada na cooperação entre as partes envolvidas e não na competição. (ÁVILA, 2002, p. 05). O novo Código Civil recepcionou a Mediação através de seus princípios norteadores, como a eticidade, a socialidade e a operabilidade. Começam a surgir luzes sobre o assunto.

A idéia do "ganha-ganha", ou seja, que todos os lados concordam e promovem o entendimento, também pode ser realizada via arbitragem, regulada no País, desde 23/09/1996, através da Lei 9.307. 


\subsection{A Arbitragem}

A origem da arbitragem, como meio de composição de litígios, é bem anterior à jurisdição pública. Pode-se dizer que ela foi norma primitiva de justiça e que os primeiros juizes nada mais foram do que árbitros.

A arbitragem no Brasil encontrava-se em desuso até que a Lei $n^{\circ}$. 9.307/96 resgatou das instituições jurídicas do país o acordo de vontades por meio do qual, as partes, preferindo não se submeter à decisão judicial, confiam ao árbitro à solução de seus conflitos de interesses. A arbitragem é uma forma de resolução de conflitos, sem qualquer ingerência do poder estatal, onde as partes litigantes, de comum acordo e no pleno e livre exercício da vontade, escolhem uma ou mais pessoas neutras, denominadas árbitros ou juizes arbitrais, estranhas ao conflito, para submeter a sua questão, sujeitando-se à sua decisão final, dada em caráter definitivo, uma vez que não cabe recurso neste sistema. "Os partícipes têm a oportunidade de apresentar seus fatos, testemunhas e arrazoados, inclusive por meio de advogados, se preferirem". (TAVARES, 2002, p. 44).

A função do árbitro nomeado será a de conduzir um processo arbitral, de forma semelhante ao processo judicial, porém muito mais rápido, menos formal, de baixo custo e onde a decisão deverá ser dada por pessoa especialista na matéria objeto da controvérsia, diferentemente do Poder Judiciário, onde o juiz, na maioria das vezes, para bem instruir seu convencimento quanto à decisão final a ser prolatada, necessita do auxílio de peritos, especialistas na matéria.

Pelo art. 852 do novo Código Civil "é vedado compromisso para solução de questões de estado, de direito pessoal de família e de outras que não tenham caráter estritamente patrimonial", artigo este que corresponde ao art. $1^{\circ}$ da Lei 9.307/96 (Lei de Arbitragem). O art. 853, com correspondência no art. $3^{\circ}$ da Lei de Arbitragem, dispõe que "admite-se nos contratos a cláusula compromissória, para resolver divergências mediante juízo arbitral, na forma estabelecida em lei especial". Este método vem sendo bastante procurado, vem crescendo, principalmente na área de comércio exterior, mas é utilizado também nas relações de trabalho, locação residencial ou comercial, compra e venda de bens em geral, contratação de serviços, seguros, inventários e questões comerciais em geral. 


\subsection{A Conciliação}

Leciona SERPA (1999, p. 97), ser a conciliação "um processo informal em que existe um terceiro interventor que atua como elo, inclusive por telefone". É a resolução de controvérsias na relação de interesses administrada por um conciliador investido de autoridade ou indicado pelas partes, que "tenta fazer com que as mesmas evitem ou desistam da jurisdição, encontrando um denominador comum". Para isto, os interessados podem desde renunciar ao seu direito, abrindo mão do mesmo em relação ao outro, ou transigir, nas bases preconizadas pela legislação. A missão do conciliador envolve a aproximação dos partícipes, ao controle das negociações, a formular propostas e dar sugestões, apontar vantagens e desvantagens, objetivando sempre a composição do litígio. Importante referir, que esta espécie de intermediação é muito utilizada no Brasil (e no exterior também), tendo inclusive previsão normativa na Constituição Federal de 1988, ao tratar de dissídios coletivos (art. 144, § 2º); e, em alguns códigos, consta o seu obrigatório reconhecimento, como no Código Processo Civil, (artigo 125, IV), que desde 1994, dispõe que devam ser envidados esforços, visando à conciliação das partes, a qualquer tempo, com o objetivo de reduzir a absurda quantidade de processos existentes, em qualquer tribunal. E, também reconhece o resultado destes esforços:

\section{Artigo 584: \\ São títulos executivos extrajudiciais: \\ $\cdots$ \\ III - a sentença homologatória de conciliação ou de transação, ainda que verse matéria não posta em juízo;}

Também existe a obrigatoriedade da conciliação nos dissídios individuais regidos pela Consolidação das Leis do Trabalho; e ela vem sendo uma das bases de sustentação da Lei 9.099/96. (artigo 57, que inclui que o acordo extrajudicial poderá ser de qualquer natureza, e que uma vez homologado por sentença, valerá como título judicial, e não apenas extrajudicial, como na antiga Lei dos Juizados de Pequenas Causas, Lei 7.244/84).

\subsection{A Negociação}

A forma mais conhecida das resoluções de disputas é a negociação. Nela, as partes se encontram diretamente e voluntariamente e, com suas idéias, estratégias, agendas e estilos buscam a solução ou o esclarecimento de determinado impasse. Pode ocorrer apenas entre os 
interessados ou estes podem se socorrer com uma terceira pessoa, um negociador ou um especialista no assunto.

É um gênero de mediação (quando realizada apenas pelas partes) ou uma mediação impura (quando o terceiro aponta a solução). A negociação também é chamada de transação, sendo forma conjunta de resolução dos problemas contidos numa relação de interesses. Neste processo onde duas ou mais partes tentam concordar sobre o que cada uma deve dar e receber, ou fazer e receber, e é possível que aconteça, e é comum, uma transação entre os litigantes.

Para que exista a negociação é preciso que exista troca de idéias e opiniões, para que surjam os desafios que são à base de um possível acordo. É também necessário um conjunto de ações - planos, reuniões, permutas, compensações e outras alternativas. A negociação se realiza através de uma ou mais incompatibilidades, isto é quando ocorrem divergências em relação a transações, para que o processo de negociação seja disparado. (MIRANDA, 2006, p 27). Assim, é preciso que se busque um acordo que satisfaça as partes, propiciando ganhos mútuos, mas para tanto é preciso considerar que o interlocutor, parte que é do processo de solução, tem necessidades, emoções e sentimentos que precisam ser satisfeitos. Posto isto, o negociador orientado para resultados leva em consideração os interesses e a vontade alheia no planejamento da negociação.

\section{Meios não adversariais de resolução de conflitos no Direito Alienígena}

Além dos métodos centrais já referidos existem outros híbridos, como o fact finding, mini-trial, o rent-a-judge, que serão tratados em outro estudo. Está clara, a real necessidade de um modelo de Justiça mais democrático, acessível e eficiente que o atual sistema judicial, em que os Tribunais não são único recurso de políticas públicas de acesso a justiça, embora devam fazer parte de um sistema integrado de resolução de litígios, junto com os métodos alternativos de resolução de disputas. Para tanto, passa-se a observar o que existe no direito comparado e o que pode vir a ser uma proposta para o Brasil.

\subsection{Fórum de Múltiplas portas}

Este modelo é de criação americana. Lecionam GOLDBERG, SANDER e ROGERS (1999, p.372) que o Fórum de múltiplas portas seja talvez o mecanismo de institucionalização sistemática dos métodos alternativos de resolução de disputas mais abrangente no âmbito do setor público. 
Trata-se de um mecanismo no qual os conflitos que chegam ao Judiciário são encaminhados para o método de disputa mais indicado para solucionar a lide. A característicachave é a sua fase inicial, no qual cada disputa é analisada de acordo com diversos critérios e encaminhada para o procedimento mais adequado. A partir daí o caso será tratado conforme o processo indicado.

É um procedimento que utiliza o princípio da adaptabilidade, ou seja, deve ser avaliada a peculiaridade de cada litígio e encaminhá-lo a um procedimento com o qual tenha "afeição", com o qual combine uma melhor percepção da justiça na composição da lide, e deva ocorrer a satisfação dos interesses buscados pelas partes. Exemplifica BARBOSA (2003 p 248):

Um caso que envolva mais aspectos emocionais do que propriamente financeiros poderá ser encaminhado para uma conciliação, ou então, um processo que diga respeito a uma controvérsia extremamente técnica, como a qualidade da turbina de um avião, poderá ser encaminhado para um árbitro especialista em engenharia aeronáutica.

Grande parte dos doutrinadores aceita que o procedimento seja adaptável, variando apenas a aceitação do grau dessa adaptabilidade, que "deve ser máximo para que o procedimento flua com celeridade e eficiência no exercício da jurisdição", conforme entende DINAMARCO (2002, p. 356).

No modelo de tribunais tradicionais, que são os existentes no Brasil, o método jurídico é utilizado tanto para os casos que por eles são bem solucionados, quanto para os que seriam mais bem atendidos por outros métodos. Assim, não se aproveitam às vantagens de cada um, não há uma otimização dos serviços prestados, neste viés. Tampouco são evitadas as desvantagens, que repousam no desconhecimento das matérias emocionais, que em muitas situações são o foco da questão individual, quando o magistrado por não conhecê-las em profundidade não tem a percepção necessária para uma melhor aplicação da justiça.

Este mecanismo do fórum de múltiplas portas busca a adaptabilidade processual em grau máximo, para atingir a solução ótima a cada caso em concreto. Esta solução é a que combina menores custos financeiros e emocionais, maior satisfação das partes com os resultados, e impede o reaparecimento da questão, ou assegura a durabilidade da solução. Racionaliza as soluções de controvérsias, pois "num mesmo tribunal encaminha diversos procedimentos e logra maximizar as vantagens e minimizar as desvantagens de cada um". (BARBOSA, idem, p. 249) 
A idéia do fórum de múltiplas portas não é nova. Em 1848, Nova York realizava o julgamento por um árbitro com direito a apelação para um juiz, e em 1952 as cortes da Pensilvânia passaram a estabelecer programas de arbitragem compulsória. Sua sistematização aconteceu apenas em 1976 e sua ampliação em 1990, com o Civil Justice Reform Act, que determinava que toda a circunscrição federal devesse possuir um plano de redução de despesas e de morosidade, e na maioria dos planos apresentados houve propostas de maximizar o uso dos métodos alternativos nas cortes. Informa CAPELLETI (1998, p.164) que "em 1992, estimativas indicavam já existirem 1.200 fóruns de múltiplas portas recebendo encaminhamento de cortes estaduais americanas".

No Brasil, o Poder Judiciário do Estado de Santa Catarina, levando em conta a experiência bem sucedida em países como Canadá, Estados Unidos e Inglaterra, em relação à utilização de métodos alternativos e não adversariais de resolução de conflitos, tem adotado a pratica da mediação familiar, nas Varas de Família, conforme Resolução nº 11/2001:

Art. $1^{o}$ - Recomendar aos Juízes das Varas de Família a instituição do Serviço de Mediação Familiar, com a participação efetiva de Assistente Social integrante do quadro do Poder Judiciário e de instituições, órgãos de comunidade e outros técnicos (Psicólogos, Pedagogos, Advogados, dentre outros), que se mostrem interessados em cooperar, de forma gratuita, na implantação e execução desse serviço.

Parágrafo único - O Serviço de Mediação Familiar poderá ser implantado nas dependências de Fóruns, nas Casas de Cidadania e, mediante convênio, nas Universidades ou outras instituições congêneres.

Em Brasília, o Tribunal de Justiça do Distrito Federal, por meio da Resolução nº 02, instituiu o Programa de Estímulo a Mediação, no qual fica estabelecido que o serviço de mediação forense será acionado a critério do juiz.

Os procedimentos utilizados nestes fóruns de múltiplas portas podem ser os mais variados (geralmente mediação, conciliação e arbitragem), pois não existe uma determinação exata quanto aos procedimentos adequados a serem usados, o que pode inclusive oportunizar a criação de novos procedimentos ou o surgimento de algum híbrido. Pode ocorrer de modo compulsório ou voluntário, com muitos ou poucos métodos oferecidos, com encaminhamento individual de cada caso ou por categoria de controvérsia, como também através de seleção do procedimento realizada pelo magistrado, por funcionários do tribunal a quem ele delegue esta tarefa ou pelas próprias partes. 


\subsection{Os Julgados da Paz}

A origem dos Julgados de Paz não é clara. Alguns historiadores dizem que surgiu no final da Idade Média, outros afirmam que datam do início do século XIX, mas especificamente "nas prescrições do Fuero Juzgo (Livro II, Titulo I, XV), que criou a figura dos mandaderos da paz, enviados pelo rei para estabelecer a paz entre as partes". (PEDRO-SO, TRINCÃO e DIAS, 2001, p. 212). A missão dos mandaderos era promover a concilia-ção e o acordo, em caso de desavenças, sem desempenharem qualquer função judicial concreta.

Outros, como LÓPEZ (1998, p.11) creditam à origem destes Julgados a figura do juiz de paz da Assembléia Constituinte da Revolução Francesa, com função conciliadora e competência reduzida a assuntos de pequeno porte. Entretanto, estes juízes de paz, posteriormente serviram de modelo a vários paises europeus, que conservaram o mesmo nome, devidamente adaptado a língua de cada nação.

Na Espanha, os Julgados da Paz foram instituídos em 1855 e foram remodelados diversas vezes, inclusive com alteração do próprio nome, passando a denominar-se julgados municipais; suas competências ganharam relevância, passando a tratar de matérias de Registro Civil e de casamentos, além de serem aumentadas para o âmbito penal. Em 1945, foi criada através de decreto, a figura do Juiz de Paz.

Em Portugal, a origem é remota, o juiz e o juiz de paz era escolhido entre os "ho-mens bons do concelho e das freguesias, reunindo funções administrativas e judiciais. O juiz de paz foi desaparecendo à medida que o poder central impôs o juiz de nomeação régia”. (PEDROSO, TRINCÃO e DIAS, 2001, p. 213).

Reapareceu em 1519, como conciliador e desapareceu de novo, com a dominação espanhola. A Revolução Liberal restaurou esta figura e o Código de Processo Civil de 1939 manteve-a, na media em que a incumbiu da missão de conciliar as partes antes de chegarem à fase do julgamento no tribunal... "juiz de paz" também poderia desempenhar as funções auxiliares do juiz de comarca. O recurso (voluntário) a conciliação do juiz de paz foi decrescendo, pelo que acabou por ser suprimido em 1961.

Mas, os juizes de paz e os Julgados voltaram a ser valorizados. A Constituição da República Portuguesa de 1976 consagrou o princípio da participação popular na administração da justiça, e no seu artigo 217 consagra expressamente a figura dos juízes populares. Coube à LOTJ de 1979, a criação dos Julgados de Paz, em seu artigo 12, $\mathrm{n}^{\circ} .2$ e dos juízes sociais 
(artigo 38, e artigo $68^{\circ}$ da Lei 82/77, de 6 de dezembro). Atualmente, vige a Lei 78/2001, que regula a organização, a competência e o seu funcionamento.

Os Julgados de Paz de hoje, são Tribunais competentes para resolver causas de va-lor reduzido (até € 3740,98) de natureza cível, excluindo as que envolvam matérias de Di-reito da Família, Direito das Sucessões e Direito do Trabalho. Atuam principalmente em questões relacionadas com: incumprimento de contratos e obrigações; responsabilidade civil (contratual e extracontratual); direitos sobre bens móveis ou imóveis (propriedade, condomínio, escoamento natural de águas, comunhão de valas, abertura de janelas, por-tas e varandas, plantação de árvores e arbustos, paredes e muros divisórios, etc.); arren-damento urbano, excetuando o despejo.Tem celeridade,baixo custo, adotam os princípios da proximidade, simplicidade, oralidade e da informalidade. Apreciam pedidos de indeni-zação cível, quando não tenha sido apresentada participação criminal ou após a desistên-cia da mesma, como, por exemplo, ofensas corporais simples, difamação, injúrias, furto e danos simples, bem como alteração de marcos divisórios. Agem em parceria com o Minis-tério da Justiça e com as Autarquias dos lugares onde estão situados.

Além da possibilidade de julgar e decidir dispõem igualmente de serviços de mediação, tendentes a tentar a resolução dos litígios ainda antes de os mesmos serem submetidos à decisão do Juiz de Paz. Este serviço de mediação pode, inclusive, abordar e tratar assuntos que não possam ser submetidos à decisão dos Julgados de Paz, dispondo, portanto de maior campo de atuação.

Nestes Julgados as partes têm que comparecer pessoalmente, podendo, no entanto, fazer-se (ou não) acompanhar por advogado. Se, na seqüência da mediação, as partes chegarem a acordo, esse acordo é reduzido a escrito, assinado pelas partes e homologado pelo juiz de Paz, valendo como uma sentença de $1^{a}$ instância. Cabe eventual recurso para o tribunal da comarca ou para tribunal especializado desde que o valor da ação seja superior à metade do valor da alçada do tribunal de $1^{\mathrm{a}}$ instância.

Embora esta redescoberta e a receptividade que vem recebendo, há os que aplaudem e os que criticam (por defender que os Julgados precisam ter em sua área de atuação conflitos de matéria penal). Mas é importante lembrar que o objetivo que se encontra na base da criação dos Julgados de Paz é mais do que a diminuição da pendência processual, é a vocação para permitir a participação cívica dos interessados e para estimular a justa composição dos litígios por acordo das partes. 
De acordo com FERREIRA, este considera que os Julgados de Paz são:

Uma alternativa de equidade (em sentido lato) que pode e deve, constituir um meio personalizado de Justiça, que procure a conciliação, que tenda a evitar e eliminar conflitos, o que pode ser mais importante que resolve-los, relativamente à paz social e pessoal. (2001, p. 5).

Os Julgados de Paz entraram efetivamente em vigor, em terras portuguesas, no ano de 2002, e foram avaliados por mais de cinco meses por um Conselho de Acompanhamento, composto por membros do Ministério da Justiça, do Conselho Superior de magistratura, pela Associação Nacional dos Municípios Portugueses. Devido a sua contribuição, na ambicionada mudança do sistema de administração da justiça, no sentido de torná-la mais acessível aos cidadãos, acredita-se que aos poucos estará ocorrendo uma expansão da sua competência territorial. Com o tempo, deverão estar presentes em todos os cantos de Portugal.

Em relação ao Brasil, a partir dos anos 80 começaram a ser discutidas as medidas para atenuar a crise do Judiciário, com vistas a torná-lo mais acessível aos cidadãos. Pode-se afirmar que já ocorreram muitas mudanças nos últimos tempos: os Juizados de Pequenas Causas (1984), que vieram a dar lugar aos Juizados Especiais Cíveis e Criminais (1995), a Lei da Arbitragem, a ampliação da conciliação na Justiça do Trabalho (as juntas de conciliação), o reforço dos poderes conciliatórios do juiz, estimulando esta atividade no curso do processo e, atualmente, a mediação e os Juizados Especiais Federais.

Previstos na Constituição Federal de 1988, e regulamentados pela Lei nº 9.099 de 26/09/1995, os Juizados Especiais Cíveis e Criminais foram criados para atender aos interesses dos cidadãos de forma mais rápida e sem burocratização.

Nos Juizados Especiais Cíveis são julgadas as causas cujos valores não ultrapassam a 40 (quarenta salários mínimos). São impedidos de julgar: causas que versem sobre direito de família, menores, heranças e inventários, falências, reclamações contra o Estado, assim como as causas trabalhistas e de acidentes de trabalho. Entretanto, podem julgar as causas que envolvam as sociedades de economia mista e as concessionárias de serviço público, as empresas de telefonia móvel, questões envolvendo bancos, planos de saúde, financeiras, condomínios e etc.

A Constituição Federal em seu artigo 98, inciso I, impôs a criação de Juizados Especiais Criminais (Lei n. 9.099, de 26.9.1995) para o julgamento de infrações penais de menor potencial ofensivo que são: a) as contravenções; e b) os crimes aos qual a lei comina 
pena máxima abstrata não superior a um ano, salvo exceções em casos em que a lei prevê procedimento especial, por incompatíveis e inconciliáveis com este rito.

Aqui importa fazer um relevante apontamento. A Lei $n^{\circ}$. 10.259, de 12/7/2001, ao instituir os Juizados Especiais Criminais na Justiça Federal em seu artigo $2^{\circ}$, $\S$ único, preceitua: "Consideram-se infrações de menor potencial ofensivo, para os efeitos desta Lei, os crimes a que a lei comine pena máxima não superior a dois anos, ou multa”. Ou seja, há duas diferenças em relação ao artigo 61 da Lei n. 9.099/95: a primeira eleva o máximo da pena abstratamente cominada, para efeito de incidência da competência especial, de um para dois anos; e, a segunda, não contém a cláusula restritiva, "excetuados os casos em que a lei preveja procedimento especial". Percebe-se que, além de ampliar o rol dos delitos de menor potencial ofensivo por meio da elevação da pena máxima abstrata cominada ao delito, a lei nova silencia a respeito das exceções, ampliando o conceito de infrações de menor potencial ofensivo.

Os dois dispositivos cuidam do mesmo assunto, mas com regras diversas: enquanto o anterior executa, reduzindo o campo de incidência da norma, a segunda generaliza, ampliandoo. Diante disso, deve prevalecer a lei posterior, mais benéfica, que derroga a anterior (C. Federal, artigo 5. ${ }^{\circ}$, inciso XL; e, Código Penal, artigo 2. ',$\S$ único). Interpretação diversa conduziria a situações de flagrante desigualdade jurídica. Assim sendo, devem ser considerados delitos de menor potencial ofensivo, para efeito do art. 61 da Lei n. 9.099/95, aqueles aos qual a lei comine, no máximo, pena detentiva não superior a dois anos, ou multa, sem exceção, ainda que tenham procedimento especial.

Não se deve esquecer que os Juizados tem como objetivo aproximar a justiça dos cidadãos. Para tanto, suas atuações devem pautar pela oralidade, simplicidade, informalidade, economia processual e celeridade, tentando sempre que possível à conciliação ou a transação, e cada Juizado dispõe de um serviço de assistência judiciária, para prestar atendimento à população em geral.

\section{Considerações finais}

Até então, o que pode ser observado nos Fóruns de Múltiplas Portas, Julgados de Paz e Juizados especiais, foram formas consensuais de resolução de conflitos, contando com a total interferência/manifestação do Judiciário. Na verdade, para os conflitantes o que importa é a pacificação dos conflitos, seja pelo Estado ou por outros meios, tanto faz. Não se trata de lutar pelo fim do monopólio estatal sobre o poder jurisdicional. 
“O Judiciário está na janela do mundo... como sistema falido na entrega da prestação jurisdicional" (ANDRIGHI, 2003, 01), e com o tempo, corre o risco de inviabilizar a própria convivência social. A jurisdição é dever do Estado. Nada impede, todavia, que a sociedade se ampare em alternativas mais rápidas e eficazes, voltando-se, ao Poder Público para a palavra final, e para o uso da força, obrigando os vencidos a cumprirem a decisão proferida, se necessário for.

Imperioso se faz, que em nível de Brasil, ocorra a inserção da Justiça Personalizada, ou seja, a criação de uma forma de justiça que pense na totalidade do ser humano, uma justiça alternativa, que ocorra de forma obrigatória, decorrente de um dos meios consensuais de resolução de conflitos - a mediação - mas com origem nas organizações sociais, empresariais e econômicas, na vontade do povo, das comunidades que clamam pela rapidez da prestação dos seus direitos. Importante dizer que a obrigatoriedade é de mediar, não de realizar acordo, se as partes não concordarem entre si, sob pena de não se tornar respeitada, considerada como uma “justiça de segunda mão".

Para que se opere uma mudança de mentalidade, que aconteça como um dever cívico, e que a via consensual passe a ser mais cultivada do que a litigiosa, é preciso promover a transformação de toda uma cultura burocrática sedimentada ao longo dos tempos, e implementar a "cultura da pacificação". Afinal, se as leis e a justiça são construções do ser humano, parece ser duvidoso que possam ser edificadas de uma única maneira.

\section{Referências Bibliográficas}

ABBAGNANO, N. Dicionário de Filosofia. São Paulo: Mestre Jou, 1970.

ANDRIGHI, Fátima Nancy. Acesso à Justiça. Juizado Especial de Pequenas Causas, Brasil. Disponível em: <http://bdjur.stj.gov.br/dspace/handle/2011/1372>. Acesso em 07.07.2006.

ÁVILA, Eliedite Matos. Mediação Familiar. Formação de Base. Apostila. Florianópolis: TJSC, 2004.

BARBOSA, Ivan Machado. Fórum de múltiplas portas: uma proposta de aprimoramento processual. In: AZEVEDO, André Gomma de (org.) Estudos em Arbitragem, Mediação e Negociação. Brasília: Brasília Jurídica, 2002, vol II.

CAPELletTI, Mauro, GARTH, Bryan. Acesso à Justiça. Trad. Ellen Gracie Northfleet. Porto Alegre: Fabris, 1988. 
DINAMARCO, Candido Rangel. A Instrumentalidade do Processo. São Paulo: Malheiros, 2002.

FERREIRA, J. O Cardona. Julgados de Paz: organização, competência e funcionamento. Coimbra: Coimbra, 2001.

GIDDENS, Anthony, BECK, Ulrich, LASH, Scott. Modernização Reflexiva. Política, tradição e estética na ordem social moderna. São Paulo: Unesp, 1997.

GOLDBERG, Stephen B.; SANDER, Frank E.; ROGERS, Nancy H. Dispute Resolution, Negotiation, Mediation, and Other Processes. In: AZEVEDO, André Gomma de (org.) Estudos em Arbitragem, Mediação e Negociação. Brasília: Brasília Jurídica, 2002, vol. II.

GRUNSPUN, Haim. Mediação Familiar. O mediador e a separação de casais com filhos.São Paulo: LTr, 2000.

LÓPEZ, Alejandro Giraldo. Los Jueces de Paz em el Pais Vasco. Fines y médios. Onati: Instituto Internacional de Sociologia Jurídica, 1998.

MARTINS, I. G. da S. Reforma Judiciária. São Paulo: Malheiros, 2003.

MEDIAR - Mediadores e Árbitros Associados Ltda. Perguntas mais Freqüentes. Disponível em: $<$ http://www.mediar-rs.com.br/atividades_interativas/perguntas.asp $>$. Acesso em $11 \mathrm{de}$ mar. 2005.

MIRANDA, Márcio. Duas Táticas para você negociar melhor. Catho Curso Executivo de Negociação on-line. Apostila de Negociação. São Paulo: Catho, 2006.

NADER, P. Filosofia do Direito. Rio de Janeiro: Forense, 2000.

PEDROSO, João, TRINCÃO, Catarina e DIAS, João Paulo. Percursos da informalização e da desjudicialização: Por caminhos da reforma da administração da justiça. Coimbra: OPJP, 2001.

REALE, M. Introdução à Filosofia. São Paulo: Saraiva, 1994.

RISKIN, Leonard. Compreendendo as orientações, estratégias e técnicas do mediador: um padrão para iniciantes. In: AZEVEDO, André Gomma de (org.) Estudos em Arbitragem, Mediação e Negociação. Brasília: Brasília Jurídica, 2002, vol. I.

SERPA, Maria de Nazareth. Teoria e Prática da mediação de conflitos. Rio de Janeiro: Lúmen Juris, 1999.

TAVARES, Fernando Horta. Mediação e Conciliação. Belo Horizonte: Mandamentos, 2002. 